\title{
APROXIMACIÓN A UNA ZONACIÓN FISIOGRÁFICA Y SU APLICACIÓN EN EL CONTROL DE IMPACTOS AMBIENTALES: EL CASO DE ALCOI
}

\author{
Enrique Matarredona Coll
}

\begin{abstract}
The propose of this study is to propose a zoning of an area of La Montaña (Alicante), taking as criteria of zonal differentiation not only the geophisic type ones -litostratumgraphy, topography- but also those of biogeographic and environmental features -climate-vegetation-without forgetting the exceptional function of man as an element of tranformation. These zonal units are dealt with from a descriptive view-point as well as from a prescriptive one, advocating a series of actions and measures which tend, on one hand, to counteract the consequences of environmental impacts (fairs, urbanization process, extractive works, incoherent reaforestation) and natural risks (floods, landslides, creeping) and on the other, to attempt for an appropriate territorial planning.
\end{abstract}

\section{RESUMEN}

El objeto de este trabajo es proponer la zonación de un sector de La Montaña (Alicante), tomando como criterios de diferenciación zonal tanto los de tipo geofísico (litoestratigrafía, topografía), como los de carácter ambiental y biogeográfico (clima-vegetación), sin olvidar la excepcional función del hombre como factor de transformación. Estas unidades zonales son tratadas tanto con una visión descriptiva como con un carácter prescriptivo que propugna una serie de actuaciones y medidas tendentes, por un lado a contrarrestar las consecuencias de los impactos ambientales (incendios, pistas forestales, actividades extractivas, proceso urbanizador, repoblaciones incoherentes) y de los riesgos naturales (inundaciones, desprendimientos, reptaciones), y por otro, a intentar una adecuada ordenación del territorio.

\section{Introducción}

El uso y abuso de los recursos naturales y el deterioro del medio ambiente son temas, frecuentemente tratados a nivel bibliográfico, que han provocado en los últimos años una 


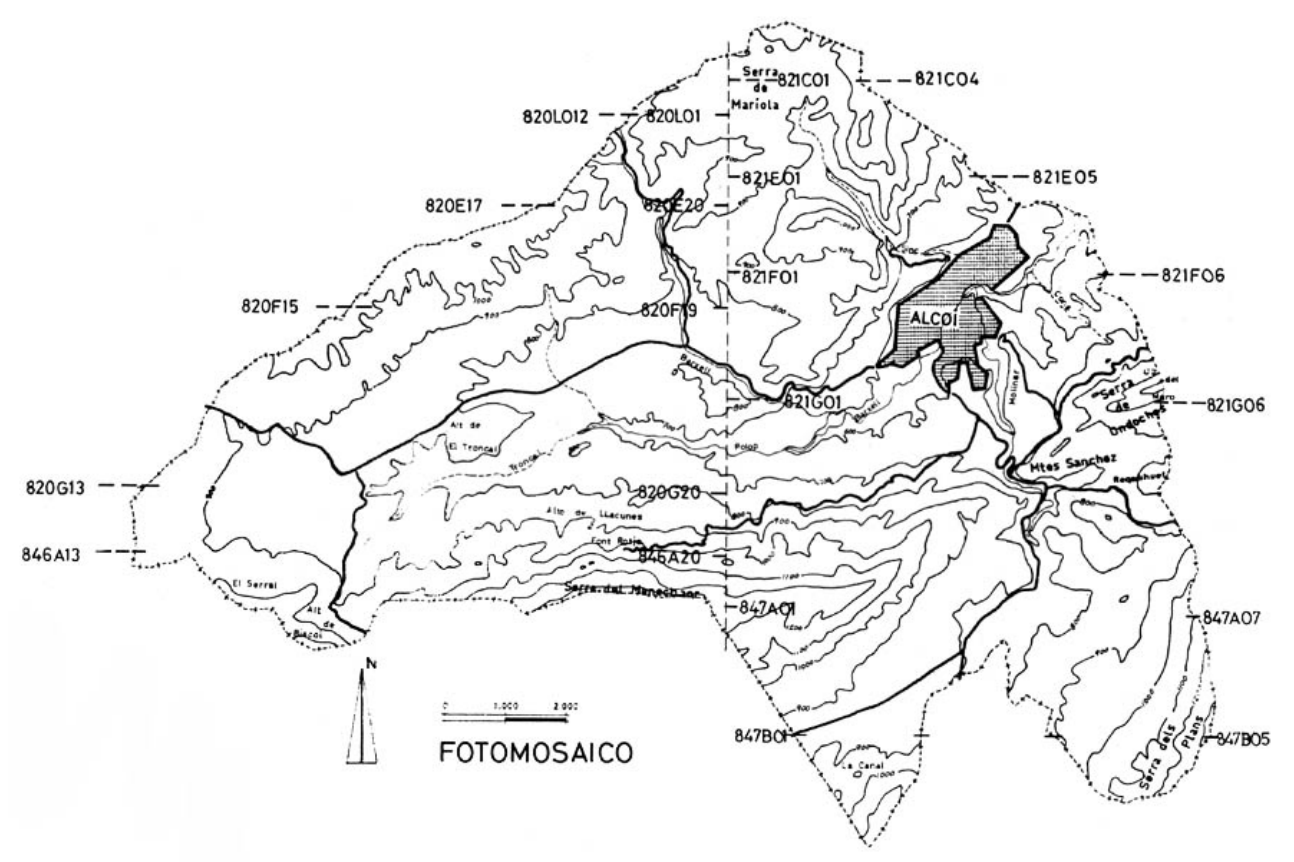

FIGURA 1 
cierta preocupación tendente a paliar no sólo el esquilme de esos recursos sino a evitar la alteración del equilibrio ecológico y la degradación del paisaje. Como quiera que, en gran medida, ese mal uso se traduce en una transformación de los parámetros del paisaje natural, acrecentando la acción de la erosión e incrementando la frecuencia de riesgos morfológicos, en este trabajo proponemos la zonación de un municipio de La Montaña alicantina tomando como criterio de diferenciación zonal tanto los de tipo geofísico (litoestratigrafía-topografía), como los de carácter ambiental y biogeográfico (clima-vegetación), sin olvidar la excepcional función del hombre como factor de transformación.

A tal fin realizamos en la primera parte del estudio un análisis de esos criterios que, en algún caso, nos ha permitido trazar unos esquemas cartográficos temáticos. La superposición de estos mapas temáticos, unida a la labor de fotointerpretación, realizada sobre los fotogramas citados en el Fotomosaico correspondiente al vuelo interministerial de 1978 a escala aproximada 1:18.000, nos sirvió para delimitar una serie de unidades homogéneas en las que se da una misma combinación de elementos distintos.

Estas unidades homogéneas -zonas- han sido tratadas puntualmente en la segunda parte, tanto en una visión descriptiva (IGME) que tenía como objetivo matizar su caracterización diferencial, como con un carácter prescriptivo que propugna una serie de actuaciones tendentes, en cada caso, a contrarrestar las consecuencias, de todo tipo, de los impactos ambientales (incendios, pistas forestales, actividades extractivas, urbanizaciones, agricultura abandonada, repoblaciones incoherentes, entre otras) y de los riesgos naturales (inundaciones, desprendimientos, deslizamientos, reptaciones) en cada una de las zonas delimitadas.

\section{Idiosincrasia del medio físico alcoyano}

2.1. Litoestratigrafía: de los afloramientos calcáreos de las cotas más altas a los depósitos margo-arcillosos de las áreas deprimidas

Los materiales que afloran en la zona de estudio pertenecen al dominio prebético, o zona más externa de las cordilleras bélicas, y se distribuyen en alineaciones montañosas de dirección SW.-NE., constituidas por materiales duros, esencialmente calizos, sobre todo en las unidades estructurales, mientras que en los valles más o menos amplios dominan los materiales blandos terciarios y cuaternarios (RODRÍGUEZ, 1977).

Los afloramientos del Keuper, de carácter diapírico, se localizan en el flanco SE. de El Serral, en el extremo SW., en una estrecha y larga banda de dirección WSW-ENE. que pasa por las inmediaciones de la Font Roja, dos manchas a la salida del Barranc del Sinc, al N. de la ciudad de Alcoi y una serie de afloramientos al SW. de ésta. Está constituido por las, típicas arcillas de tonos rojizos y verdosos con tonalidades ocasionales pardo-amarillentas entre las que aparecen intercalados yesos más o menos cristalizados.

Dolomías cenomanienses -de tonos predominantemente grisáceos- con esporádica presencia de margas y calizas se extienden por el borde septentrional, mientras que un potente banco de calizas de tonos claros, de edad turoniense, con infrecuentes intercalaciones margosas, se localizan en el extremo sur y forman parte de la Serra de La Canal. También aparece el Cretácico Superior por medio de unas biomicritas senonienses que afloran en la Serra de La Canal y en el extremo occidental de la Font Roja, así como por calizas microcristalinas 


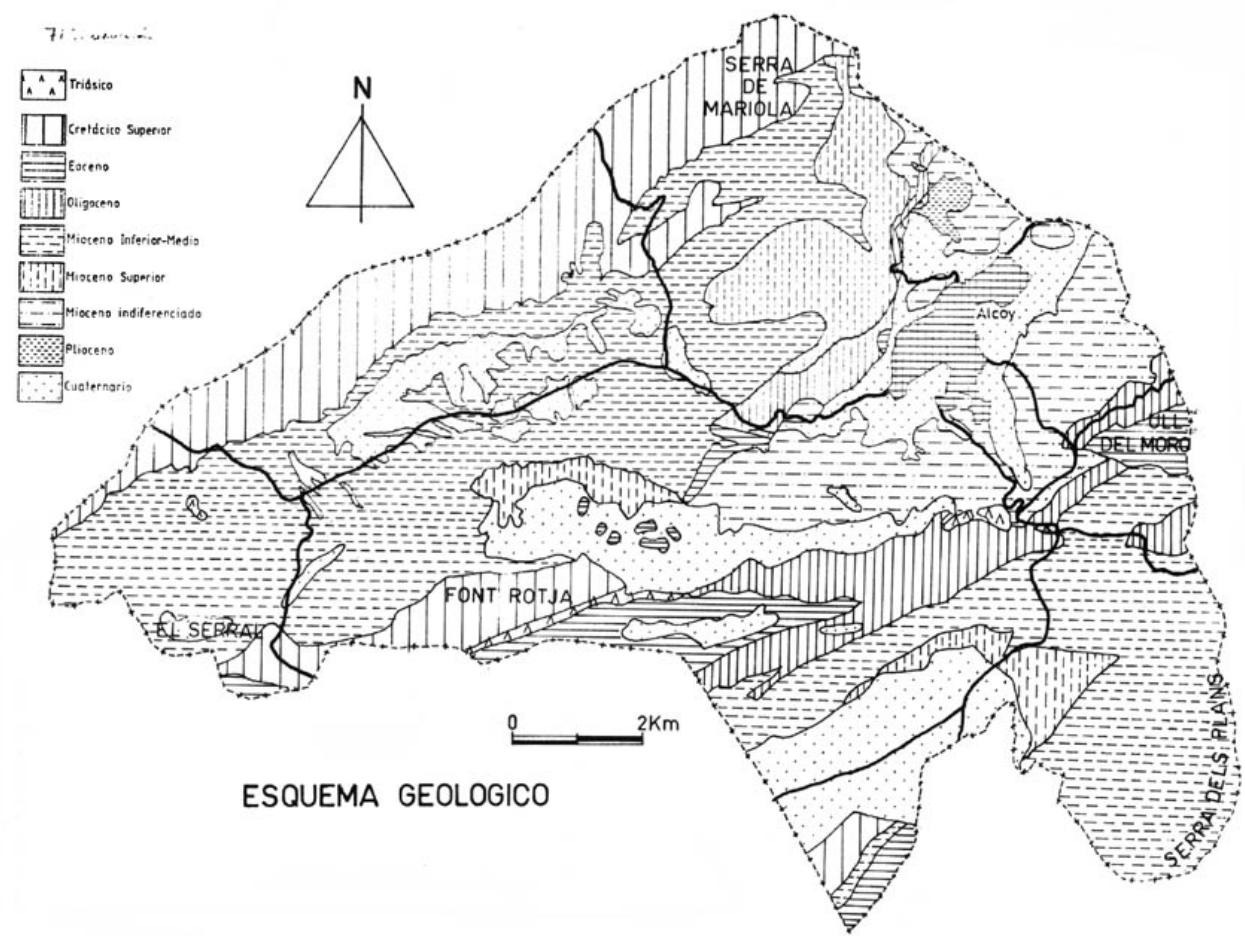

FIGURA 2 
con algunos bancos de margas amarillentas que se distribuyen en el flanco septentrional (Serra de Mariola) y en la formación de calcoarenitas bioclásticas, biomicritas grises y arcillas rojas localizadas en El Salt (W de Alcoi).

El Paleoceno está representado en la Serra de La Canal por un conjunto de arcillas margosas de tono verdoso y margas ocre-amarillentas; terrenos datados en esta edad -Danienseforman una banda de dirección WSW-ENE que se localiza en el paraje de los Morros de Vista Bella (Font Roja). Adyacente a ésta se encuentra un paquete de calcoarenitas bioclásticas y margas amarillentas montienses.

Los afloramientos del Eoceno proliferan en diversos puntos: Font Roja, Serra de La Canal, El Salt y en la Serra de Ondoches. Está constituido por un paquete formado por calcoarenitas bioclásticas, calizas pararrecifales y dolomias.

Terrenos oligocenos se extienden, asimismo, de forma diversa. Así, un oligoceno calizomargoso se localiza en la Serra de Sambenet, Sant Antoni, Montes Sánchez y Altet del Regadihuet; mientras que otro oligoceno, compuesto por calizas, conglomerados y margas de tono salmón se extiende al pie del Ull del Moro y en la franja dispuesta entre El Salt y Senellés (N. de Alcoi).

En las estribaciones meridionales de la Serra de Sambenet y en la Serra dels Plans afloran calizas detríticas y calizas margosas del Mioceno. Una serie de margas limosas de tonos blancos y beige claro -burdigalienses- se disponen en estratos de espesor variable al pie de la Serra dels Plans (al SE). Asimismo, margas blancas del mioceno inferior ocupan la Foia de Alcoi y depresiones localizadas entre la Serra dels Plans, Altet del Regadihuet y Montes Sánchez.

El Mioceno medio está presente en las margas blancas ubicadas al pie de Mariola (sector centro-septentrional), en los materiales de carácter fuertemente detrítico que se distribuyen por la mitad NW del término: pie de Mariola, El Serral, W de la Font Roja, N de Las Canteras y piedemonte de la Serra dels Plans; y margas blancas compactas extendidas en dos anchas franjas que recorren las depresiones por donde discurren las carreteras Alcoi-Banyeres y Alcoi-Ibi.

Areniscas calcáreas tortonienses en potentes bancos se localizan en Las Canteras (NW de Alcoi) y a lo largo de El Troncal (W del término). Por otro lado, depósitos pliocenos rellenan la zona de El Troncal y el sector NE de Alcoi; se trata, sobre todo en este último caso, de arcillas rojas con niveles conglomeráticos y areniscosos.

Los depósitos de piedemonte presentan en su litología gravas, cantos y arcillas, a veces bastante cementadas, que se caracterizan por su angulosidad y naturaleza monogénica. Los más extensos se localizan en la ladera norte de la Font Roja, N de Alcoi, ladera NW de los Montes Sánchez y Ull del Moro, pie de Mariola y vertiente meridional de la Serra de Sant Antoni.

Canchales de cantos angulosos sueltos aparecen en puntuales parajes del Ull del Moro, Altet del Regadihuet, Las Canteras y Font Roja. Finalmente, depósitos aluviales y terrazas con una litología de gravas, arenas, arcillas y limos, se relacionan con los cursos de los ríos actuales $\mathrm{y}$ los fondos de barrancos.

\subsection{Las pendientes como factor de la erosión y de la dinámica de laderas}

El criterio topográfico nos permite calibrar el valor de las pendientes como factor de 


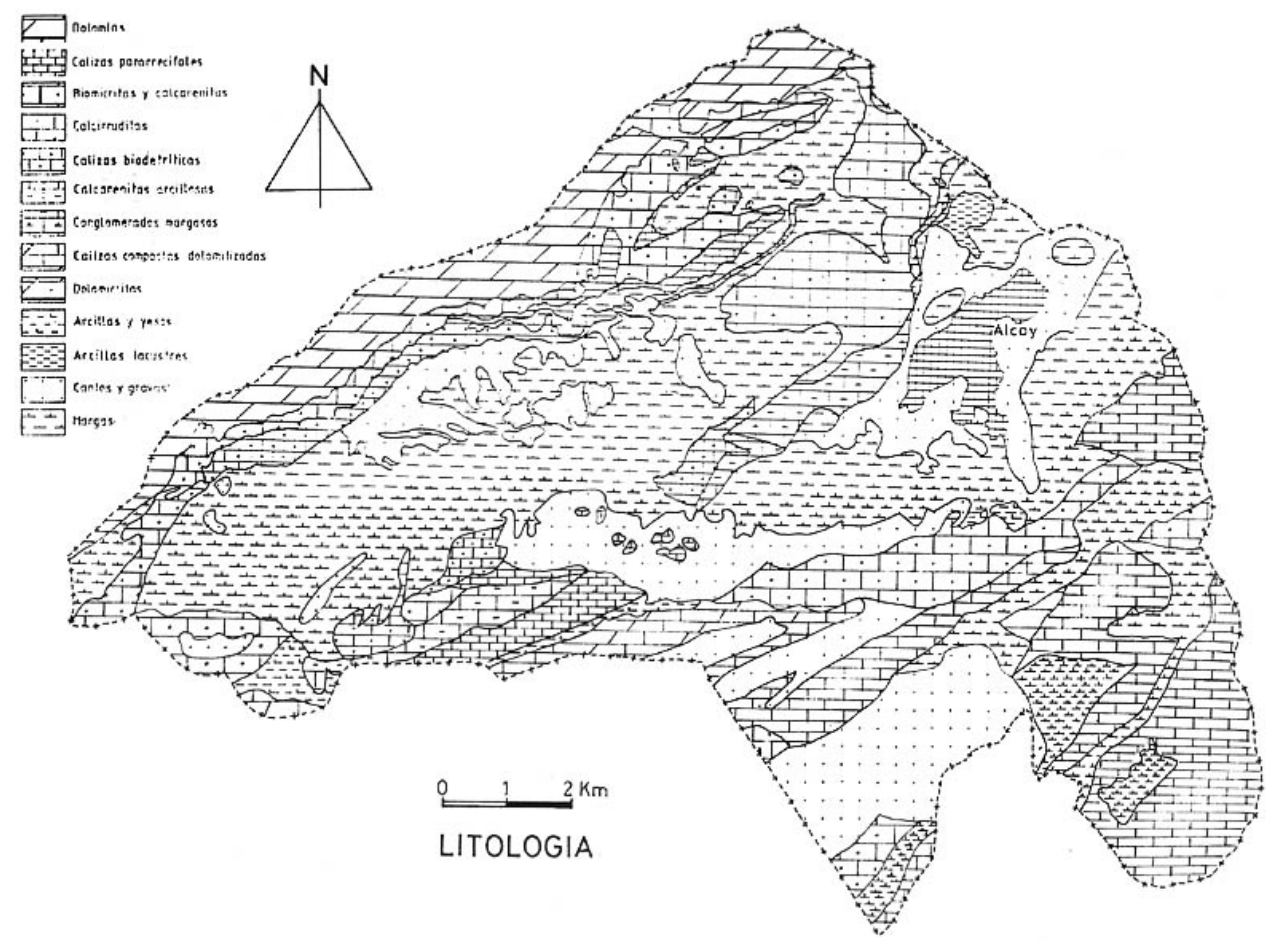

FIGURA 3 
notable importancia en las formas de modelado y en la evolución de las laderas, aspecto esencial en un área que, sometida a una intensa tectónica, muestra unos escarpes acusados en las vertientes septentrional y oriental.

La pendiente de una vertiente influye tanto en la mayor o menor regulación de la infiltración como en la acción del agua de arroyada que, según los casos, puede provocar el desgajamiento de los materiales en función de su naturaleza, y su posterior transporte (GUALDA, 1988); aunque en este aspecto no hay que olvidar la acción de la cobertera vegetal como agente de control de la dinámica de vertientes, de ahí la diferenciación, en otro apartado de este estudio, de una tipología de vertientes atendiendo a la cobertura del tapiz vegetal.

Con todo, la estabilidad de los materiales que cubren una pendiente es una cualidad que expresa su mayor o menor tendencia a permanecer in situ, mientras que la inestabilidad queda definida por el grado de susceptibilidad al movimiento. La importancia de la estabilidad es grande en los estudios de ordenación del territorio por cuanto que los riesgos de desprendimientos y de movimientos en masa imponen serias restricciones al desarrollo de las actividades constructivas y a la asimilación de usos del suelo (COSTA-MATARREDONA, 1989).

En la inestabilidad influyen, en esencia, dos fuerzas: el esfuerzo cortante que tiende a producir el deslizamiento y la resistencia al corte que se opone a aquél. De la relación entre ambas surge la mayor o menor estabilidad de la pendiente con la particularidad de que el esfuerzo cortante depende del grado de inclinación, del aumento de la masa o incluso de la alternancia de materiales; mientras que la resistencia al corte puede disminuir por la existencia de fallas o las acciones sobre la vegetación (LA ROCA, 1980).

En el área estudiada se han observado pendientes de muy diversa índole: desde aquellos espacios que no superan los $10^{\circ}$ identificados como zonas llanas y de pendiente suave- que pueden aparecer como cuencas de recepción de sedimentos y que, en algún caso, -por su perfil allanado- generan problemas de estancamiento de las aguas pluviales, hasta aquellas zonas (barrancos, escarpes, laderas abruptas) que se sitúan por encima de los $30^{\circ}$, como es el caso de las paredes que jalonan el Barranc del Sinc en las que se aprecia una actividad morfológica intensa, tanto por influencia de la tectónica como de la activa erosión mecánica, con los riesgos inherentes a fenómenos de desprendimientos y caídas de bloques. En el umbral intermedio -entre $10^{\circ}$ y $30^{\circ}$ - se distingue una serie de vertientes identificadas con escarpes de tipo medio y laderas montañosas de inclinación modesta en las que se observa la formación de depósitos de piedemonte, derrubios de ladera y depósitos de gravedad. En conclusión, los factores que controlan las fuerzas que impulsan al deslizamiento o desprendimiento pendiente abajo (DUNNE-LEOPOLD, 1978) son el grado de pendiente, su acentuación por inclinaciones tectónicas, el desmonte por procesos geomórficos o antrópicos, la concentración de la escorrentía, los procesos de descalce, entre otros.

\subsection{Continentalidad y altura como modificadores del clima mediterráneo y sus consecuencias en la morfogénesis \\ El clima de la zona, enmarcado dentro del tipo mediterráneo, presenta ciertos rasgos} diferenciales de continentalización, determinados tanto por la propia situación geográfica que 


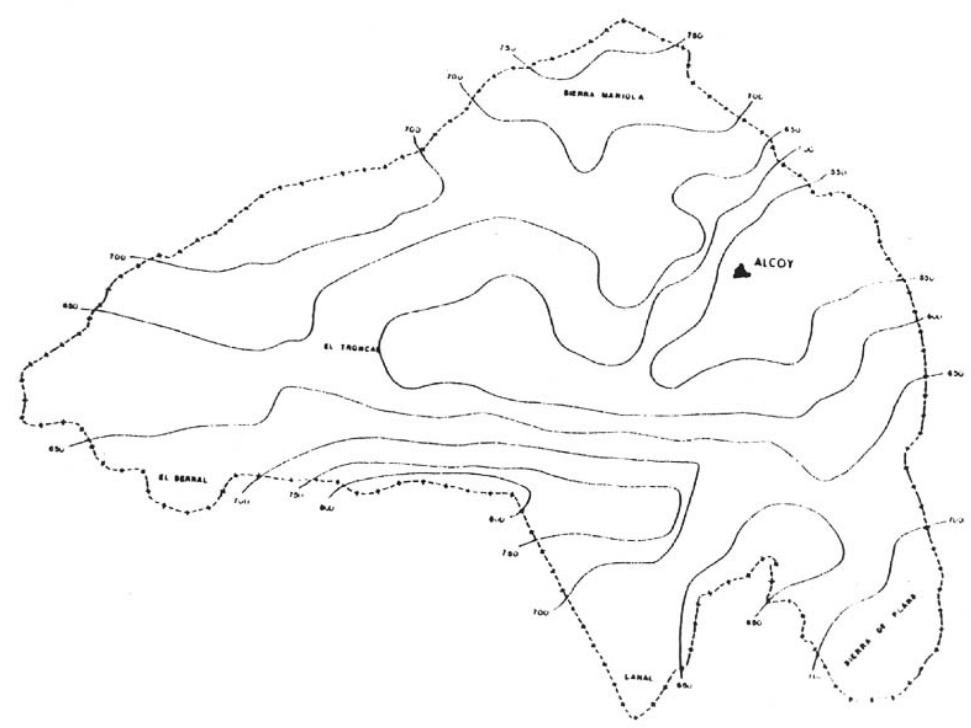

FIGURA 4 a: Mapa de Isoyetas anuales $\left(1 / \mathrm{m}^{2}\right)$
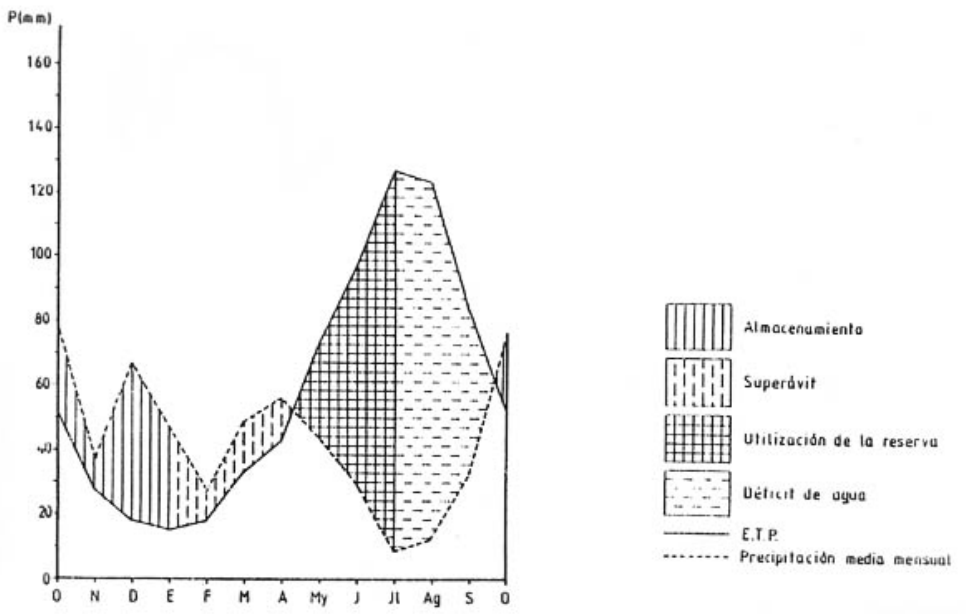

FIGURA 4 b: Climograma de Thomthwaite: Alcoy 
se manifiesta en inviernos fríos y veranos secos y cálidos, como por el relieve que establece diferencias térmicas de una vertiente a otra, así como incrementos en los registros pluviométricos en las vertientes de barlovento, incremento en el que juegan mucho la orientación de los valles y la dirección dominante de los flujos húmedos.

El análisis del mapa de isoyetas muestra un mínimo de $500 \mathrm{~mm}$./año en el fondo de la Foia de Alcoi y un máximo de $800 \mathrm{~mm}$. en las cumbres de la Font Roja -al amparo del efecto orográfico, la situación o el posible concurso de precipitaciones invisibles (CLAVERO, 1981)-. En el resto de alineaciones montañosas (Serra de Mariola, Els Plans, Sant Antoni) las precipitaciones oscilan entre 700 y $800 \mathrm{~mm}$.

El ritmo anual de las precipitaciones es irregular: al lado de un máximo absoluto otoñal que concentra el $30 \%$ del total, el invierno es menos lluvioso y la primavera aparece como máximo secundario, mientras que el mínimo estival es muy acusado (CLAVERO, 1979). Por otro lado, es significativo el papel de las precipitaciones de gran intensidad horaria causantes de deslizamientos y movimientos de masas en las laderas con pendientes superiores a $20^{\circ}$ y causa directa del crecimiento desaforado del Serpis al incidir estas precipitaciones sobre una cuenca que ofrece pronunciados declives en sus vertientes.

Ahora bien, a veces no es suficiente conocer los totales y el ritmo pluviométrico para aproximarse a la realidad de las precipitaciones; es necesario, además, un referencia a la irregularidad interanual puesta de manifiesto en "secas" que se suceden según ciclos más o menos amplios (1961-62, 1968-69, 1984-85) y se muestran alternantes con "años húmedos" (1959-60, 1972-73, 1986-87), comportamiento que tiene su reflejo en el Ríu Serpis que conjuga en su elevada irregularidad las consecuencias de duros estiajes y furiosas avenidas.

Por otro lado, el régimen térmico refleja una progresiva gradación altitudinal que queda patente en la desaparición de ciertas especies vegetales que se muestran poco resistentes a las heladas (algarrobo). Alcoi registra una temperatura media anual de $14,8^{\circ} \mathrm{C}$ y una amplitud térmica de $15^{\circ} \mathrm{C}$ (enero $7^{\circ} \mathrm{C}$ y agosto $>22^{\circ} \mathrm{C}$ ). Con todo, pese a las medias citadas, los inviernos son algo rigurosos, no siendo extraños los fenómenos de heladas desde noviembre a abril.

Añadir que los espacios de montaña introducen modificaciones en los parámetros climáticos que se traducen en la presencia de puntuales microclimas, fruto de la posición de protección de ciertos valles a la penetración de los flujos fríos del norte, o la buena predisposición de ciertas laderas a los efectos de la insolación; hechos que tienen su reflejo en la aparición de ciertas especies vegetales o en la desaparición de otras.

Fenómeno bastante común, que marca la personalidad climática del espacio, es la frecuente presencia de una densa niebla en el fondo de los valles que se forma a causa de una inversión de temperaturas en las primeras decenas o centenas de metros de la troposfera.

Los vientos dominantes son del NE (22\%), SW (18\%) y SE (14\%), estando acompañados de precipitaciones los del primer y segundo cuadrantes. En más de la mitad de las ocasiones, la velocidad del viento se sitúa entre 0 y $5 \mathrm{Km} / \mathrm{hora}$, mientras que, por el contrario, flujos superiores a los $30 \mathrm{Km} /$ hora sólo suponen una frecuencia del $2 \%$.

El análisis del índice de evapotranspiración de Thornthwaite, que presenta el gran interés de definir numéricamente el alcance de la sequía y sus consecuencias agrícolas, contando con los intercambios biológicos entre el suelo y las plantas, permite comprobar que desde principios de octubre la precipitación es suficiente para subvenir la evapotranspiración, por lo que el superávit llega hasta abril, mes a partir del cual empieza a consumirse para paliar 


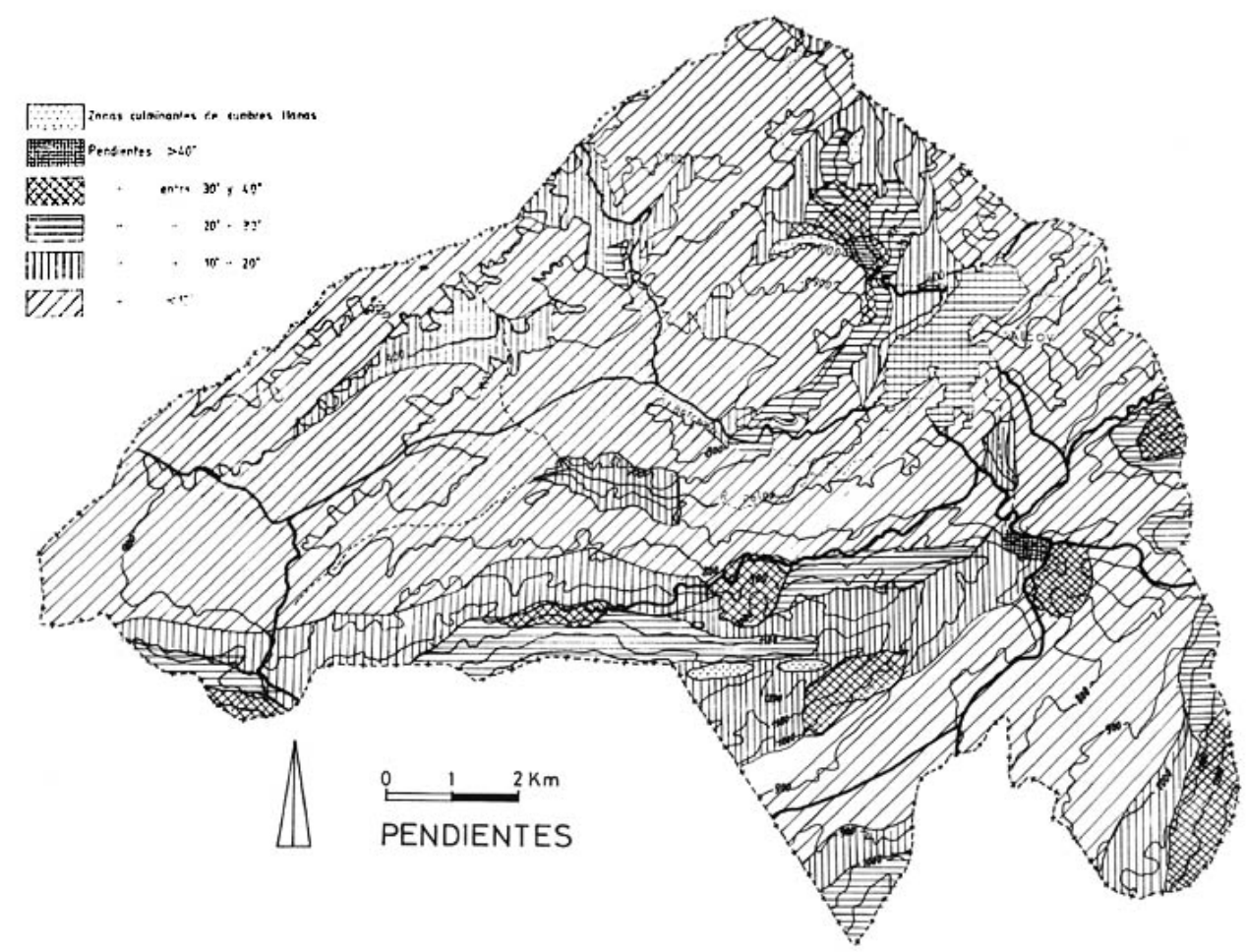

FIGURA 5 
la sequía; desde julio aparece un déficit -una vez consumida toda la reserva y a causa de la penuria estival- que llega hasta comienzos del nuevo año agrícola.

\subsection{Vegetación: entre los condicionamientos lito-topográfricos, los factores medio-ambientales y la acción antrópica}

La vegetación está determinada por las condiciones climáticas. Veranos secos, fuerte insolación y precipitaciones insuficientes son, a nuestro juicio, los factores de limitación de la vida vegetativa, subsidiarios a unos condicionamientos lato-topográficos que tienen su natural influencia.

Así, podemos hacer una primera distinción entre superficies forestales arboladas y áreas serranas de matorral o Barriga. En efecto, en las vertientes septentrionales, más húmedas, en torno a los $1.000 \mathrm{~m}$., se forma un bosque climax dominado por un quejigo (Quercus faginea, spp. valentina), acompañado de encinas (Quercus ilex), fresnos (Fraxinus ornus) y algún tejo o teix, sobre un sotobosque denso con marfull, hiedra, madreselva (FOLCH, 1981).

Asimismo, podemos indicar que el primitivo bosque climax de encinas -mediterráneoconstituyó antaño buenas formaciones vegetales en las montañas alcoyanas y el topónimo de "carrasca" o sus derivados aluden claramente a ello (Carrascal de Alcoi), pero hoy están reducidos a manchas aisladas y muchas veces completamente degradados (laderas de la Serra de Mariola y dels Plans).

Esta asociación-Quercetum ilicis rotundifoliae- representada por la carrasca, resistente al frío y poco exigente en humedad, sólo se conserva bien en el Carrascal de Alcoi -por las expresas prohibiciones de tala que se han impuesto desde antiguo-, espacio en el que aparece también el galler (Quercus valentina), un roble poco exigente y de hoja semicaduca.

De este encanar sólo quedan los topónimos, pues a menudo ha sido sustituido por el pinar de pino carrasco (Pinus halepensis), especie que actúa hoy en día de disclimax con un sotobosque, pobre en especies, donde dominan la aliaga y el enebro. Esta sustitución de la encina puede haberse producido tanto por la propia degradación del bosque climax como por la excesiva aridez, factores que son más fácilmente soportables por el pino. Por otro lado, esta degradación de los encanares determina la aparición de un matorral que, a veces, constituye el sotobosque de pinares actuales, formado a base de especies de la alianza Rosmarino-Ericion: el romer (Rosmarinus officinalis), el coscoll (Quercus coccifera), el timó (Thymus vulgaris), entre otros.

Con todo, la especie arbórea más frecuente es el pino carrasco, genuino mediterráneo, de follaje claro, hojas cortas y tronco torcido. Compone las masas forestales más importantes de la zona, pese al retroceso que ha experimentado por talas e incendios. En el Carrascal de Alcoi se muestra predominante sobre la encina hasta $\operatorname{los} 1.000 \mathrm{~m}$. y tiende a desaparecer a más altura. Menor incidencia tiene el pino piñonero (Pinus pinea), de copa redonda y espesa, que forma pequeños bosquetes en la base de la Serra de Mariola. Por su parte, el pino laricio (Pinus clusiana), más exigente en humedad (CLIMENT, 1985), sólo se encuentra en grupos reducidos o pies aislados en Mariola.

Un caso particular es la vegetación de las cimas más altas, por encima de los $1.000 \mathrm{~m}$., ocupadas por un matorral, frecuentemente espinoso, -adaptado tanto al frío como a la 
incidencia del viento- que presenta formas aerodinámicas de espesas almohadillas: el coixi de monja, de flores azules; la argilaga, de flores amarillas, y a menor altitud, la variedad lavandulifolia de la salvia (MATARREDONA, 1988).

En los canales de los barrancos, el esbarcer (Rubus ulmifolius) forma densas masas entretejidas, acompañadas de juncos, chopos (Populus alba) y algún olmo (Ulmus minor), aunque últimamente los olmos cultivados proliferan por todos los lechos, especialmente en los meandros del Serpis, aguas abajo de Alcoi.

El papel de la cobertura vegetal es esencial a la hora de valorar los efectos de la morfología climática, toda vez que ciertas especies rupícolas de la comunidad Asplenietea rupestris pueden favorecer la erosión mecánica de las rocas mediante la acción de cuña de sus raíces (GUALDA, 1988), mientras que, por otro lado, el desarrollo del tapiz vegetal aporta los ácidos húmicos necesarios para que el agua de arroyada incremente su poder erosivo, fundamentalmente sobre el roquedo calcáreo dominante en el área.

Por el contrario, ciertas especies de la comunidad Thlaspetea rotundifoli ejercen una función de fijación de clastos en áreas dominadas por depósitos de ladera. En este sentido, si existe un suelo lo suficientemente desarrollado para generar una espesa capa vegetal, ésta puede llegar a fosilizar y frenar los riesgos de deslizamientos y controlar los lóbulos de solifluxión.

La ausencia de cobertura vegetal sobre las vertientes acelera el proceso de denudación y posibilita la actuación incontrolada del agua de arroyada, de tal modo que si la competencia del roquedo es escasa (margas, arcillas, yesos) existen riesgos indudables de que se formalice un paisaje abarrancado, sólo colonizado por raquíticas praderas de Thero-Brachipodetalia.

Estas consideraciones unidas a otros criterios (pendientes, litología, antropización, aterrazamientos) permiten matizar la existencia en la zona de vertientes de tipología distinta en función de su grado biostásico o rhexistásico (GUALDA, 1988):

- vertientes biostásicas localizadas en reducidos sectores de umbría en la Serra dels Plans, La Canal, El Serral y, sobre todo, la zona del Carrascal de Alcoi, donde la existencia de una cobertura edáfica apropiada y la suficiente humedad permite el desarrollo de un manto vegetal que, en el caso de ciertas especies esclerófilas montanas, contribuye a fosilizar las vertientes, coartando el riesgo de posibles desplazamientos o deslizamientos.

- vertientes semicubiertas que se extienden por todo el sector norte, así como en un pequeño espacio situado entre El Serral y la Serra del Menetjador. Se trata de vertientes que no tienen la suficiente riqueza edáfica que posibilite una espesa cubierta vegetal; de ahí que ésta sea abierta y facilite, por ello, procesos de disolución bioquímica que producen la abrasión del roquedo.

-vertientes rhexistásicas extendidas por una franja central que cruza de W.a E, así como una pequeña área situada al norte de La Canal y la Serra dels Plans. El predominio de materiales deleznables (margas) y depósitos aluviales (cantos y gravas) y su posición en el fondo de áreas deprimidas contribuyen a incrementar la acción del agua de arroyada facilitando el encajamiento de los aparatos fluviales al amparo de un medio que se muestra desnudo y proclive a los riesgos de erosión mecánica.

- vertientes rocosas localizadas en ciertos espacios de Mariola y en el sector oriental y meridional del Menetjador. Las pendientes acusadas y el roquedo superficial explican la 


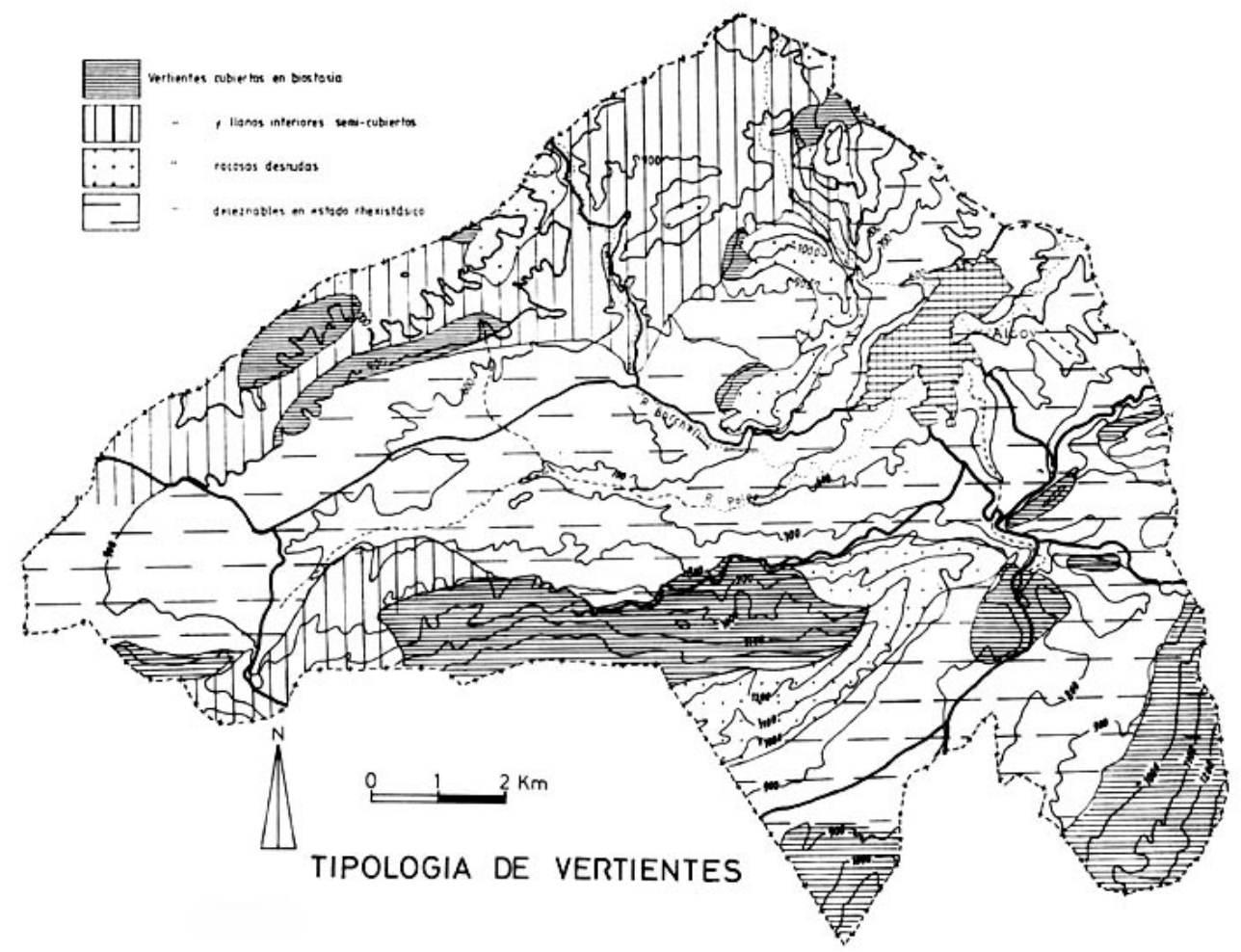

FIGURA 6 
existencia de estas áreas desnudas en las que predomina la erosión mecánica y donde no están ausentes los riesgos de desprendimientos en función de la altitud, pendientes, grado de tectonización y condicionantes climáticos.

\subsection{El hombre como factor de degradación y transformación del paisaje}

El impacto del hombre sobre el medio implica no sólo una acción directa sino que, a la vez, es fuente de degradación que puede acrecentar los factores socioeconómicos y el progreso técnico insuficientemente controlado (TRICART, 1979).

La degradación antrópica afecta principalmente a parámetros biogeográficos -vegetación y suelos- y supone, en algunos casos, el reemplazo de la vegetación natural por una agricultura que absorbe menor cantidad de energía morfogenética, al tiempo que deja la tierra desnuda de cobertura vegetal durante las primeras fases del ciclo vegetativo de las plantas, a lo que cabría añadir la degradación edáfica, toda vez que el cultivo reduce los aportes orgánicos que benefician al suelo, con lo que se rompe el equilibrio edafogenético y se pueden incrementar los riesgos de arroyada. Con todo, la situación más crítica se produce cuando el suelo está desnudo; en ese momento ningún obstáculo vegetal se opone a la concentración de la arroyada (NEBOIT, 1983).

El hombre representa para las comunidades bióticas un factor ecológico decisivo que contribuye ampliamente a modificar su distribución (LACOSTE, 1973). Independientemente de ciertos trabajos que tienden a facilitar la evolución progresiva de la biocenósis (repoblación, restauración de suelos), la acción humana tiene, a menudo, por consecuencia una degradación de ésta (talas, pastoreo, incendios).

En muchas áreas del ámbito estudiado, el abandono de zonas agrícolas marginales, actualmente no rentables, plantea serios problemas para la conservación del suelo. Estas zonas se dedican a secano extensivo en terrenos con pendientes acusadas y con cultivos semiabandonados (almendro-olivo), que dejan la mayor parte de la superficie del suelo sin protección y sin ningún tipo de medidas de conservación frente a los agentes erosivos que acentúan los desprendimientos o "trencs" de los taludes. El abandono de las terrazas, antaño cultivadas, y su rápida destrucción por la arroyada ha contribuido a una disminución de la percolación y a una pérdida de laminación de las ondas de crecida, así como a un incremento de los coeficientes de arrastre y su depósito en las zonas bajas, con los consiguientes problemas en las infraestructuras (redes viarias cubiertas por flujos arcillosos). El abandono masivo de roturaciones marginales alcanza cotas peligrosas: millones de toneladas de suelo se arrastran hacia espacios extracomarcales, "beneficiando" áreas más bajas o creando problemas de aterramiento en embalses próximos (Beniarrés).

Otro factor de impacto son los incendios forestales que en los últimos años han supuesto la destrucción de varias hectáreas tanto de bosque arbolado como de matorral y monte bajo ( 5 Ha. de monte arbolado el 20 de agosto de 1982; casi 1 Ha. de pinar el 15 de mayo de 1981 en la finca La Peña, entre otros, según datos de Protección Civil de Alicante). El problema es grave si se tiene en cuenta que el fuego elimina la cubierta vegetal que protege el suelo frente a la erosión y, además, altera sus propiedades físico-químicas aumentando su erosionabilidad.

Es, asimismo, significativo que la expansión del núcleo urbano alcoyano, la aparición de 
urbanizaciones de tipo residencial (Estepar en La Canal Baja; El Baradello y El Mas del Sargento en las proximidades del Barranc de Bocairent; Cotes Altes, entre otras), así como la proliferación indiscriminada de "segundas residencias" ha podido contribuir, en cierta medida, a impermeabilizar estos terrenos (caminos asfaltados, superficie construida) con lo que se han incrementado los débitos de la escorrentía por un mayor aporte instantáneo superficial.

Señalar, igualmente, que las prácticas agrícolas que excluyen medidas de control de la erosión también son un factor a considerar. En efecto, el hombre, mediante el barbecho -que desprotege temporalmente el suelo de una cubierta vegetal-, el sistema de arado fue en determinadas ocasiones facilita la labor de la arroyada-, el abuso de fertilizantes -que degrada la estructura del suelo-, la quema de rastrojos y matorral -que puede incrementar la arroyada a expensas de la escorrentía hipodérmica y supone un factor de riesgo de incendios-, contribuye de forma desaforada en el proceso degradante del medio.

\section{ZONACIÓN FISIOGRÁFICA}

\subsection{Zona A1. Formaciones montañosas calizas de carácter escarpado y rocoso}

Ocupa gran parte de las elevaciones montañosas de la zona: Serra de Mariola (N), Alts de Soterrani y de La Reptana (sector NW), Alt del Castellar (al W. de Alcoi), El Serral (en el extremo SW), y ciertas elevaciones en el flanco meridional como los Morros de Vista Bella, la Font Roja, Mont de Sant Antoni, Ull del Moro, Altet del Regadihuet y las sierras de La Canal y dels Plans. Asimismo, aunque con una alternancia de materiales calizos duros y niveles blandos, se extiende por dos áreas bien determinadas: en los Morros de Vista Bella y al pie del Ull del Moro.

El factor común diferenciador de esta zona radica en el carácter escarpado y rocoso, eminentemente calizo, de los materiales integrantes, los cuales, eventualmente, presentan episodios conglomeráticos, areniscosos y margosos. El análisis lito-estratigráfico muestra una variada gama: dolomías grisáceas con bancos de margas y calizas de espesor variable del Cenomaniense, estratos de calizas maestrichtienses de tonos blanquecinos, bancos alternantes de calizas nodulosas y margas amarillentas paleocenas, calizas pararrecifales eocenas (Serra de Ondoches), areniscas calcáreas bioclásticas y dolomías eocenas (Font Roja), conglomerados calizos oligocenos muy cementados (Mont Orents), y calcoarenitas de tonos beiges del Mioceno, entre otros.

Pese a ello, en los Morros de Vista Bella y en el Ull del Moro se aprecia la coexistencia de materiales de competencia diferente -duros y blandos- en proporciones significativas, pese a que estratigráficamente la naturaleza de sus componentes sea diversa: calizas margosas eocenas entre las que aparecen margas y arcillas de tonos verdosos y niveles de arena se extienden por la ladera septentrional del Morro de Vista Bella; mientras que en el Ull del Moro se observa una alternancia de materiales oligocenos -niveles margosos rojizos y blanquecinos y calizas beige grisáceas con conglomerados-.

El criterio topográfico corresponde a unas vertientes que presentan un predominio neto de pendientes superiores a $9^{\circ}$ o $10^{\circ}$ que, en el caso de las elevaciones de Font Roja, Plans, Mariola y Sant Antoni, se sitúa en torno a $10^{\circ}-25^{\circ}$, valores éstos que marcan el carácter modal 


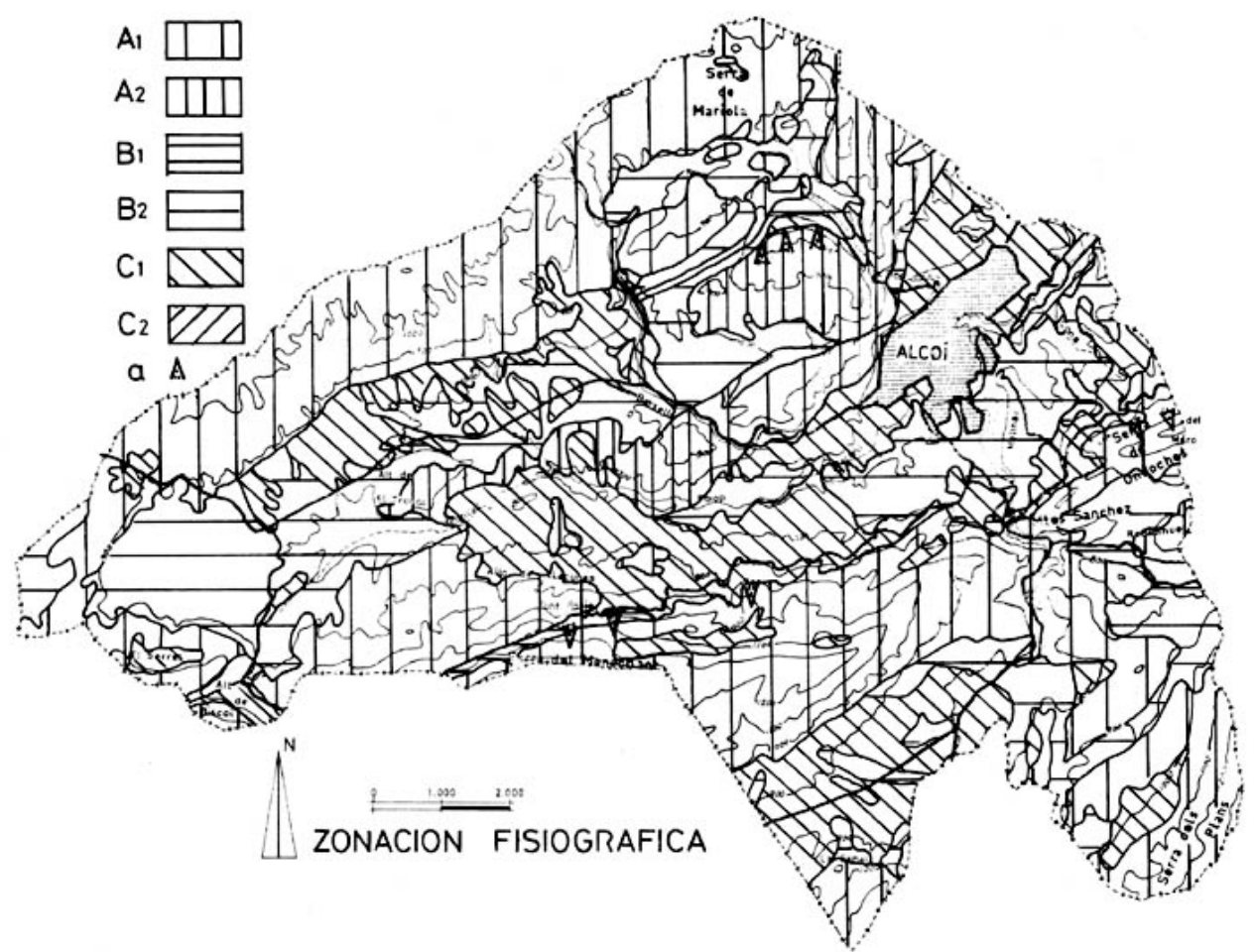

FIGURA 7 
y definen la frecuencia de taludes subverticales que justifican tanto los desprendimientos por gravedad como la alimentación de canchales y derrubios de ladera observados en el paisaje serrano. Por otro lado, al pie del Ull del Moro se desarrollan profundos abarrancamientos por erosión de los niveles blandos de margas oligo-miocenas sobre las que resaltan los estratos más duros de calizas y areniscas.

La red de avenamiento se marca por una serie de arroyos y barrancos que tienen su tramo alto en esta zona: Calvo, Regall, Cona, Sinc, Bocairent, son algunos de los más significativos. Todos ellos funcionan con un carácter espasmódico típico de las ramblas mediterráneas.

La escorrentía varía a tenor de la permeabilidad del conjunto que puede considerarse alta debido tanto a la naturaleza calcárea del substrato, como a su grado de tectonización. El avenamiento se muestra favorable y se realiza por escorrentía superficial y por percolación a través de las fracturas.

Los procesos de evolución natural posibles en esta zona son: los desprendimientos de bloques, al amparo de unos buzamientos elevados y unas pendientes de ladera subverticales, (desprendimientos eventuales fruto de la fuerte tectonización de las calizas y de los procesos de descalce debidos a la erosión de niveles infrayacentes poco competentes), y los deslizamientos o desprendimientos por descalce característicos de aquellas formaciones que muestran una alternancia de estratos duros y blandos. En las zonas abarrancadas son frecuentes las reptaciones, es decir, deslizamientos de la capa arcillosa superficial a favor de los entumecimientos y retracciones sucesivas por aumento o disminución de la humedad. Por otro lado, fenómeno bastante común suele ser el transporte y depósito de materiales desprendidos en las terrazas de cultivo que quedan así, en ocasión de precipitaciones de tipo torrencial, recubiertas por una capa de material poco fértil.

La dureza de las calizas, la acusada topografía, los ajustados escarpes y los fuertes desniveles son algunos de los factores que condicionan la presencia de unos suelos raquíticos que, por su posición y características, tienen un nulo aprovechamiento agrícola. Son los litosuelos que se presentan asociados a xerorendzinas y pardo calizos en función de las pendientes. Solo en sectores de menor inclinación, esos esqueléticos suelos han podido evolucionar -ayudados por una topografía y climatología adecuadas- hacia unos suelos pardo calizos forestales, con notable desarrollo del horizonte humífero superficial, que predominan en el Carrascal de Alcoi y son el factor de sustentación del ecosistema del Parque Natural de la Font Roja.

Como quiera que la morfología se presenta abarrancada, las pendientes fuertes y las vertientes -con la excepción del área del Carrascal, Els Plans y el Alt de Soterrani- solo "semicubiertas" de un tapiz vegetal protector, el control de los riesgos naturales (incendios, deslizamientos, desprendimientos) pasa por una política de repoblación forestal coherente (CEBALLOS, 1960) que combine especies resinosas y frondosas y contribuya a una regulación de la dinámica de laderas, así como por el establecimiento de taludes de fijación que impidan la positiva acción de la erosión en procesos de desprendimientos por descalce y controle los recubrimientos arcillosos que se conectan a los deslizamientos de piedras y tierra.

Asimismo, resulta particularmente interesante la declaración como Parque Natural del paraje de la Font Roja y el control de su uso como espacio recreativo, sin olvidar, por supuesto, que se hace necesario extremar las medidas de vigilancia precisas en la prevención de incendios en esta zona -célula natural del ecosistema de La Montaña-. 


\subsection{Zona A2. Formaciones tabulares de tipo detrítico con predominio de conglomerados}

Los terrenos que ocupan esta zona abarcan una franja que se extiende al sur de la C-3313 entre el Alt de El Troncal y El Salt; además cubre otra amplia área al norte y noroeste de Alcoi: El Baradello y la Lloma de Cotes Altes.

El rasgo distintivo de la unidad son las rocas detríticas, areniscas y conglomerados que estructuran su litología. Materiales que en El Troncal están representados por conglomerados heterométricos muy cementados entre los que se intercalan niveles areniscosos y margosos muy delgados; en cambio, en Cotes Altes, areniscas calcáreas tortonienses forman potentes bancos con una fracturación bien patente.

Dominan las formas tabulares -retazos de glacis- con los bordes seccionados por fuertes pendientes e incluso paredes subverticales; pendientes que en el sector occidental se sitúan entre $\operatorname{los} 8^{\circ}$ y $24^{\circ}$ y que se suavizan hacia la mitad oriental $\left(4^{\circ}-8^{\circ}\right)$. En Cotes Altes pueden superar los $25^{\circ}$, a modo de imponentes farallones que dominan el Barranc del Sinc.

Existe una serie de barrancos, más o menos encajados, entre ellos el citado del Sinc, prolongación meridional del Barranc del Toro originado en Mariola. Las formaciones de esta unidad son permeables debido al diaclasamiento y el avenamiento es positivo y se lleva a cabo por escorrentía muy activa.

Los desprendimientos de bloques constituyen el proceso natural más frecuente en las laderas del Sinc y están presentes, asimismo, aunque con menor envergadura, en los pequeños barrancos que vierten aguas al Troncal. En general, se trata de movimientos extremadamente rápidos que tienen su origen en taludes verticales en los que se desarrollan grietas a favor de diaclasas y fracturas que progresan hasta producir un fallo en la resistencia a tracción de la masa, que provoca la caída de los bloques.

Los condicionantes litoestructurales, la morfología glacificada del relieve, los afloramientos rocosos y la existencia de fuertes pendientes en el borde de los relieves tabulares, junto a unos esqueléticos suelos pardo calizos y xerorendzinas, determinan una capacidad de uso mediana vinculada a espacios muy puntuales.

En este punto se propugna el control de actividades extractivas -en áreas del Barranc del Sinc- impacto ambiental de gran magnitud, al tiempo que se hace constarla necesidad de unos procesos de repoblación forestal con especies adecuadas.

\subsection{Zona B1. Afloramientos triásicos con una componente lítica de tipo arcillo-yesoso}

Estructurada por una serie de afloramientos que se localizan en las inmediaciones de la carretera Alcoi-Ibi (al SE de El Serral), en una franja paralela a la pista forestal de la Font Roja (en su tramo final), al lado de la N-340 (entre los K.129 y K.130) y en las proximidades del Barranc del Sinc.

La unidad de la zona está impuesta por el criterio litoestratigráfico: predominio de materiales del Keuper constituidos por arcillas de tonos rojos y verdosos con yesos. Eventualmente aparecen lentejones interestratificados en las margas miocenas. Los afloramientos de la Font Roja presentan recubrimientos coluviales integrados por arcillas y gravas de $1 \mathrm{a}$ $3 \mathrm{~m}$. de espesor. En cualquier caso, estos afloramientos tienen carácter diapírico y la extrusión se ha producido por inyección del material a través de las fracturas provocadas por 
las distintas pulsaciones tectónicas que también reactivaron, en gran medida, la actividad halocinética.

Las pendientes, de valores diferentes en los distintos afloramientos, alcanzan los $24^{\circ} \mathrm{en}$ la Serreta Vella facilitando, junto al carácter poco competente y deleznable de los materiales, profusos abarrancamientos. La red de avenamiento está formada por cortos arroyos, más o menos encajados, que discurren sobre materiales impermeables.

Dada la naturaleza de éstos, pueden ser normales los procesos de deslizamiento de taludes o laderas, particularmente en condiciones climáticas adversas determinadas por precipitaciones de carácter paroxismal. Como quiera que los fenómenos erosivos muestran alta dinamicidad sobre estos materiales, es lógico pensar que los procesos de reptación, observados en algunos puntos, puedan ser normales en zonas acarcavadas.

Esta morfología abarrancada, las fuertes inclinaciones (en algún punto del orden de $25^{\circ}$ ) y las características impermeables de los materiales infrayacentes, contribuyen a que las formaciones edáficas -xerorendzinas de escasa profundidad y menor fertilidad- ofrezcan una baja capacidad de uso y estén sometidas a un alto riesgo de erosión edáfica. Por todo ello, se estima que en esta zona son convenientes tanto tareas de repoblación que contribuyan a su fijación y a una menor erosionabilidad de los suelos, como labores de fijación de taludes en los sectores más pronunciados y desprotegidos.

\subsection{Zona B2. Depresiones margosas de topografía allanada}

Ocupa una importante extensión en la zona de estudio, destacando la Foia de Alcoi (al E y S. de la ciudad), así como determinadas manchas localizadas en las depresiones que enlazan las elevaciones montañosas: W del Alt de El Troncal, S de El Baradello, Plá de Giner, zona comprendida entre los Montes Sánchez y el Regadihuet, entre otras.

En general, la zona se fundamenta por el predominio de margas miocenas del Tap, difícilmente diferenciable en la Foia de Alcoi en dos series por la ausencia de niveles calizos y detríticos, unidad estratigráfica que incluye margas masivas y compactas con frecuentes nódulos calizos que circunstancialmente presentan variaciones litoestructurales; así, en el sector situado al SW de Alcoi -zona de la umbría del Manco- aparecen intercalaciones de arcillas margosas de tonos ocres, mientras que en la Serreta Vella se observan intercalaciones delgadas de margocalizas.

En otros ámbitos, fuera de la Foia, las margas, más o menos arenosas, se corresponden con dos niveles estratigráficos: Burdigaliense (Tap 1) y Serravalliense (Tap 2) perfectamente caracterizados. Se presentan en estratos con suaves inclinaciones, encontrándose en ocasiones muy laminadas, con estructura hojaldrada y fuerte tectonización.

Desde el punto de vista tectónico, el sector de la Foia puede ser entendido como un relleno de la gran fosa estructural que se extiende por Cocentaina y Muro, mientras que el resto del sector -depresiones intramontanas de enlace- presenta estructuras sinclinales suaves, con mayor inclinación de los estratos en la zona de contacto.

Dentro de una topografía más o menos allanada, la morfología es abrupta por la profusión de los abarrancamientos que, a modo de profundas cicatrices, diseccionan el conjunto posibilitando unos niveles de pendiente que se muestran dispares: al pie de la Serra dels Plans (Mas de la Cueva y Mas de la Pastora) las pendientes alcanzan los $26^{\circ}$; en la Foia de Alcoi 
sobresale el abancalamiento de las laderas en pendientes que ofrecen un grado de inclinación entre $14^{\circ}$ y $25^{\circ}$.

La zona se encuentra atravesada por los ríos Barxell, Molinar y Serpis, que aparecen en gran parte encajados, con fuertes pendientes longitudinales, en particular en el Molinar. A ellos afluyen barrancos de carácter temporal entre los que destacan el de la Salut, el de Balilis y el de Caña. En el límite occidental se ubican el Barranc Calvo y el de El Troncal.

La permeabilidad es baja tanto por porosidad intergranular como por fisuración, produciéndose importantes encharcamientos en zonas abancaladas y áreas deprimidas con ocasión de precipitaciones de tipo torrencial.

Son frecuentes los deslizamientos donde las pendientes sobrepasan los $20^{\circ}$ (LA ROCA, 1980), reptaciones en zonas abancaladas por desprendimientos de los bordes debido a su saturación en momentos de lluvias intensas, reptaciones en márgenes de barrancos con pendientes de $10^{\circ}$ a $20^{\circ}$, provocadas por desprendimientos de la capa superficial alterada tanto por la saturación como por el impacto del agua de lluvia, y deslizamientos planos en los cauces encajados.

Pese a la existencia de fuertes pendientes en los bordes de los aparatos fluviales encajados, el sector ofrece una tipología allanada que contribuye, en gran medida, a posibilitar un abancalamiento amplio (sobre todo al W) beneficiado a su vez por unos suelos pardo calizos superficiales que dominan en las escamas tectónicas y unas xerorendzinas margosas. Ambos ofrecen una capacidad de uso elevada -con las naturales limitaciones impuestas en zonas de máxima pendiente- puesta de reflejo en el secano aterrazado que define el paisaje agrario alcoyano.

La frecuencia de deslizamientos y reptaciones al socaire tanto de las margas miocenas dominantes como de los niveles de inclinación en las áreas de borde pueden controlarse mediante la construcción de muretes de piedra seca en las terrazas -como mecanismo de protección a esta dinámica-, así como con el empleo de taludes de fijación -sobre todo en los márgenes de la red viaria, bastante propensos a este tipo de riesgos-. Por otro lado, y dado que en esta zona se encajan muchos barrancos que tienen sus cabeceras en las estructuras calcáreas colindantes, sería aconsejable la construcción de presas de derivación para contribuir así a laminar la escorrentía de las avenidas que pueden generar problemas en el curso bajo.

\subsection{Zona C1. Depósitos coluviales y de ladera de espesor variable}

Esta zona se extiende entre la ladera norte de la Serra del Menetjador y las estribaciones meridionales de Mariola. También se localizan manchas más o menos extensas en la depresión por la que discurre la carretera Alcoi-Banyeres y en el sector limitado por las sierras de Sambenet, Els Plans y La Canal. Otros menos importantes se ubican al pie de la sierra de Ondoches y Ull del Moro. Incluimos también depósitos de ladera puntualmente localizados en Las Canteras, la Font Roja y Ull del Moro (CALVO, 1987).

Integran esta unidad depósitos de piedemonte de edad cuaternaria o pliocuaternaria y sedimentos pliocenos localizados en ambas márgenes del Troncal y al norte y noreste de Alcoi; así como depósitos de ladera y conos de deyección en los que sobresale la coexistencia de niveles conglomeráticos o brechoides más o menos cementados y niveles de arenas li- 


\begin{tabular}{|c|c|c|c|c|c|c|c|c|c|c|}
\hline$\frac{a}{3}$ & & 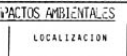 & Whocsteatigentis & Troogan in & NoR OL OG IA & Noroloorta & 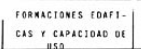 & accion an r Rop 1 Ce & R11560s & proputsias \\
\hline$\lambda_{1}$ & 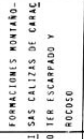 & 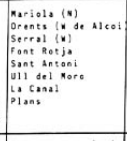 & 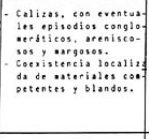 & 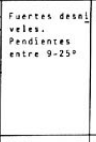 & Abartantaniestos & 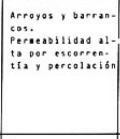 & 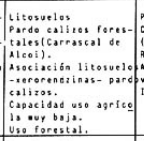 & 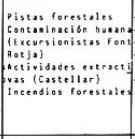 & 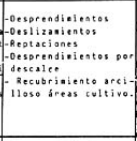 & 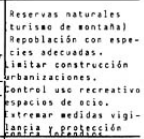 \\
\hline$i_{i}$ & 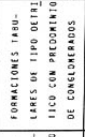 & 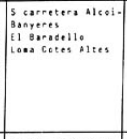 & 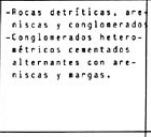 & 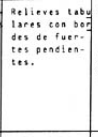 & 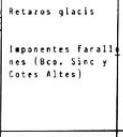 & 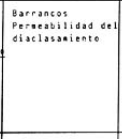 & 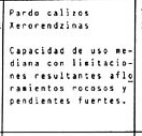 & 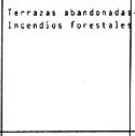 & 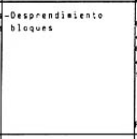 & 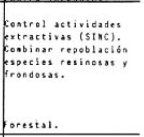 \\
\hline 1 & 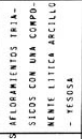 & 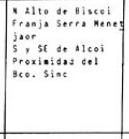 & 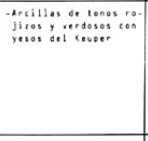 & 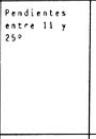 & 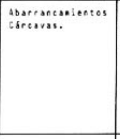 & 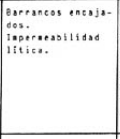 & 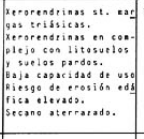 & Incenesios rorestales & 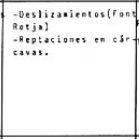 & 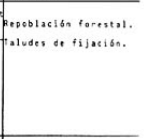 \\
\hline$i_{2}$ & 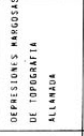 & 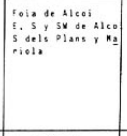 & -Nergas Diecenss & 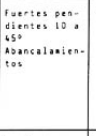 & Pans/112acos & 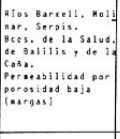 & 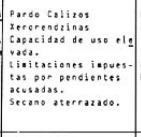 & 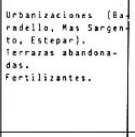 & Repteciones. & 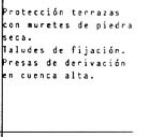 \\
\hline$c_{1}$ & 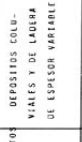 & 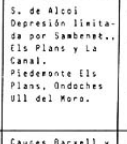 & 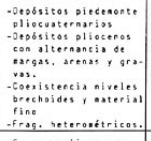 & 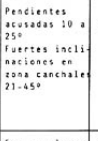 & Canstales & 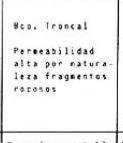 & 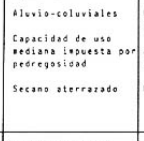 & 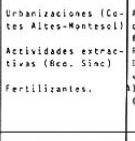 & 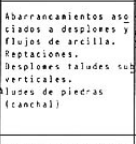 & 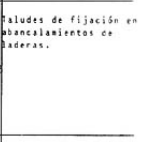 \\
\hline$i_{2}$ & 等 & 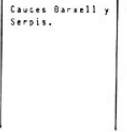 & 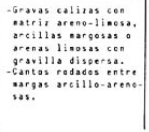 & formes planses & 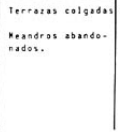 & Dressje oceptable & 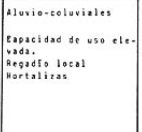 & 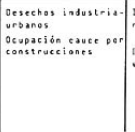 & 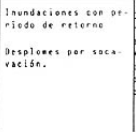 & 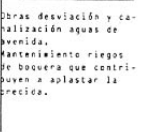 \\
\hline
\end{tabular}

CUADRO I 
mosas o arcillosas y arcillas. Por su parte, los canchales se muestran como acumulaciones de fragmentos heterométricos y angulosos de calizas, sueltos superficialmente y retenidos en profundidad bien por factores de tipo biótico (BERNABE, 1977) o por procesos de cementación.

Las observaciones de campo permiten comprobar el carácter errático de las formaciones, con importantes cambios laterales y verticales de facies. Los efectos de la tectónica reciente pueden apreciarse en unos depósitos pleistocenos localizados al NE de Alcoi en los que aparecen saltos decimétricos o incluso métricos que destacan por la presencia de encostramientos.

Los rasgos morfológicos son variados ya que los depósitos de piedemonte de la Font Roja y del Troncal presentan un relieve acusado con pendientes superiores a $15^{\circ}$, que contribuyen a una accesibilidad dificultosa y a un uso no intensivo. Al norte de Alcoi, en el área de contacto con la zona A1, se alcanzan pendientes de hasta $24^{\circ}$, formalizándose taludes verticales que enmarcan arroyos excavados en los materiales pliocenos. Los depósitos de ladera localizados en el Ull del Moro presentan pendientes de $22^{\circ}$, mientras que en la Font Roja y en Las Canteras se sitúan entre $25^{\circ}$ y $45^{\circ}$ lo que puede contribuir tanto a su funcionalidad actual por gravedad como a su inaccesibilidad (ROSSELLO, 1967).

Los tipos de inestabilidad que se pueden dar en este sector se reducen a abarrancamientos a los que se asocian desplomes y flujos de arcilla, deslizamientos en algunos taludes como consecuencia de su saturación, reptaciones en bancales subsiguientes a precipitaciones intensas, desplomes en taludes verticales y desprendimientos de bloques de niveles duros por erosión de los materiales infrayacentes más débiles (BERNABE-CALVO, 1979).

Los depósitos coluviales predominantes, la aparición de niveles brechoides, la heterometría de los fragmentos, la inestabilidad de las laderas, el predominio de vertientes deleznables en estado rhexistásico, justifican la existencia de unas formaciones edáficas pobres que ofrecen una capacidad de uso mediana, tan sólo mejorada en ciertos espacios donde la formación de suelos aluvio-coluviales en conjunción con algún pardo calizo posibilita un cierto aprovechamiento agrícola.

El tipo de materiales -depósitos de piedemonte- y el grado de dinamismo de las estructuras reflejado en reptaciones, desplomes, flujo de arcillas, aconsejan la construcción de taludes de fijación en los abancalamientos de ladera, así como labores de repoblación necesarias para lograr la retención de estas laderas.

\subsection{Zona C2. Terrazas y depósitos aluviales}

Esta zona se relaciona con los depósitos aluviales y terrazas fluviales de los cauces más importantes (Barxell y Serpis, sobre todo), aunque cartográficamente se ha representado, por condicionamientos impuestos por la escala de trabajo, dos sectores: uno en el curso del Barxell-Barranc de Bocairent y, otro al NE de Alcoi en una franja sinuosa del Serpis que llega hasta Cotes Baixes.

Pese a la dificultad que supone la ausencia de cortes naturales claros que permitan analizar las características litológicas de estas acumulaciones, se estima que los aluviones de los cursos mayores ofrecen un nivel de gravas calizas con matriz areno-limosa de espesor más o menos variable sobre un paquete de arcillas margosas o arenas limosas. Las terrazas del 
Serpis incluyen lentejones de cantos calizos entre margas arcillo-arenosas, mientras que en el Barxell las terrazas bajas son arcillo-limosas con cantos calizos dispersos (BERNABE, 1975).

Presenta formas planas con cierto escalonamiento: las formas de los aluviones menores suelen ser planicies que ocupan el fondo de los valles. Aparecen retazos de antiguos meandros hoy abandonados a los que se da un aprovechamiento agrícola. En general es una zona que ofrece claros riesgos de inundación, con períodos de retorno de cinco o seis años. Se observan esporádicos desplomes por socavación de carácter muy localizado.

La morfología plana, su posición en áreas bajas, los depósitos de variado origen y un drenaje aceptable, podrían ser algunos de los factores que explican la existencia de unos suelos de aporte -de tipo aluvio coluvial-, que posibilitan un buen aprovechamiento agrícola-clásico espacio del regadío local-, ubicado en ambas márgenes del Serpis.

Como quiera que el mayor riesgo de estas zonas bajas se conecta a las avenidas provocadas por copiosas precipitaciones, se propugna la construcción de obras de desviación y canalización de dichas aguas, así como, en la medida de lo posible, el mantenimiento, aguas arriba de la ciudad de Alcoi, de los riegos de boquera que contribuyen a aplastar la crecida de los débitos.

\section{Conclusiones}

La zona de estudio es un conjunto de depresiones margosas encajadas entre las aristas calizas de Mariola, El Serral, Alt de Biscoy, Menetjador, Sambenet, Plans y Ull del Moro, y seccionadas por la red fluvial del Serpis que discurre con una trayectoria SW-NE. Un conjunto de escarpes y llanos, enlazados por la red hidrográfica, que incluye zonas con altas precipitaciones (Font Roja) y áreas menos regadas, con un paisaje natural que, si bien se muestra degradado -fundamentalmente por acción antrópica- también es cierto que conserva algunos manchones relictos de su antiguo dominio (As. Quercetum ilicis rotundifolia), en un marco edáfico dominado tanto por la naturaleza calcárea del substrato como por la propia topografía.

Así pues, y de un modo general, se consideran dos grandes zonas: las estructuras montañosas de tipología caliza y topografía más acusada (Zonas A1 y A2) y las depresiones margosas y piedemontes de morfología más allanada (Zona B2 y C1). En ambas los riesgos se vinculan a la dinámica de laderas y se manifiestan en procesos naturales que comportan movimientos de masas -desprendimientos, deslizamientos, reptaciones, desprendimientos por descalce, abarrancamientos asociados a desplomes y flujos de arcilla, desplomes de taludes verticales-, o inundaciones en zonas de menor cota.

Los factores motrices de esta dinámica se asocian a la tipología de los materiales (alternancia calizas-margas), a las fuertes pendientes, a la morfología, a los niveles de permeabilidad y drenaje, a las formaciones edáficas, a la cobertura vegetal y a la acción antrópica (incendios, actividades extractivas, técnicas agrícolas, roturaciones abandonadas, desechos industriales y urbanos).

Las propuestas, encardinadas en una coherente planificación y ordenación del territorio, se resumen en: 
- $\quad$ la construcción de taludes de fijación en abancalamientos de ladera y en la red caminera.

- $\quad$ en una repoblación mixta que combine especies resinosas (pino) y frondosas (encina).

- $\quad$ extremar los cuidados y protección de especies bióticas del Parque Natural de la Font Roja.

mantener bajo control, y dentro de unos límites, el uso recreativo del espacio de ocio de este enclave.

- $\quad$ extremar las medidas de vigilancia y protección contra los incendios forestales.

- limitar la construcción de "segundas residencias", declarando como Suelo No Urbanizable de Especial Protección ciertas áreas todavía preservadas de tal degradación que mantienen aún el equilibrio armónico entre sectores rurales, integrados en el paisaje, y el medio natural.

- $\quad$ replantear un control racional de las actividades extractivas para que ocasionen el menor impacto ambiental.

construir obras de derivación y canalización de aguas de avenida que contribuyan, de alguna forma, a aplastar las crecidas que ocasionalmente pueden provocar inundaciones en zonas bajas de los cauces del Serpis, Barxell y Polop, entre otros.

\section{Bibliografía}

ALMELA, A. y otros, Mapa geológico de España. E 1:50.000. Hoja $n^{o} 821$ (Alcoy), I.G.M.E., Madrid, 1975,31 pp.

BERNABÉ MAESTRE, J. M., "Vegetación y morfología en las pedrizas de montaña media", Actas de la II Reunión Nacional del Grupo Español de Trabajo del Cuaternario, Jaca 15-20 sept. 1975, Madrid, 1977, pp. 33-40.

BERNABE MAESTRE J. M., "Red fluvial y niveles de terrazas en la depresión Cocentaina-Muro (Valls d'Alcoi)", Cuadernos de Geografia, $n^{\circ} 16$, Univ. de Valencia, 1975, pp. 23-39.

BERNABE MAESTRE J.M. y CALVO CASES, A., “Algunos ejemplos de vertientes cantil- talud en los Valls d'Alcoi”, Cuadernos de Geografia, Univ. de Valencia, 1979, pp. 127-137.

BIROT, P. y SOLE SABARIS, L., "Recherches sur la morphologie du Sud-Est de l'Espagne", Rev. Geographie des Pyrenees et $d u$ Sud-Ouest, t. XXX, fasc. 3, Toulouse 1959, pp. 159-284.

CALVO CASES, A., Geomorfología de las laderas en la montaña del País Valenciano, Ed. Alfons el Magnanim-Institució Valenciana d'Estudis i Investgació, 1987, 301 pp.

CEBALLOS, I., "Repoblación forestal española en los últimos veinte años”, Estudios Geográficos, Madrid, 1960, pp.497-507.

CLAVERO PARICIO, P.L., "Influencia del Mediterráneo en las precipitaciones del Pais Valenciano", Notes de Geog. Física, no 1, Barcelona, 1979, pp. 13-24.

CLAVERO PARICIO, P.L., "Distribución espacial de la radiación solar y las precipitaciones en el Macizo de Alcoy”, Actas del VII Coloquio de Geografia, A.G.E., Pamplona, 1981.

CLIMENT i GINER, D., Les nostres plantes, Inst. Estudios “Juan Gil-Albert”, Alicante, 1985.

COLODRON, I. y otros, Mapa Geológico de España. E 1:50.000. Villajollosa (847), I.G.M.E., Madrid, 1981,26 pp.

COSTA, J. y MATARREDONA, E., “Avenidas y problemas de taludes en la ciudad de Alcoy”, Avenidas fluviales e inundaciones en la cuenca del Mediterráneo, Instituto Universitario de Geografía, Alicante, 1989, pp. 195-206.

DÁVILA, J.M., Evolución urbana de Alcoy (s. XIII-XVIII), Tesis de Licenciatura, Universidad de Alicante, 1986, $268 \mathrm{ff}$.

DEFONTAINES, P., “Los horizontes de trabajo en el Macizo de Alcoy”, Estudios Geográficos, 1958, pp. 275-281. 
DUMAS, B., Le Levant Espagnol. La génese du reliev, C.N.R.S., Univ. de Paris, 1977, 520 pp.

DUNNE, T. y LEOPOLD, L., Water in Enviromental Planning, W.H. Freeman and Co., San Francisco, 1978.

DUPUY de LÔME, E. y SÁNCHEZ LOZANO, R., Mapa Geológico de España. E 1:50.000. Alcoy (821), I.G.M.E., Madrid, 1957, 99 pp.

FOLCH i GUILLEN, R., La vegetació dels Països Catalans, Ketres, Barcelona, 1981.

GUALDA, C. La Sierra de Mariola, Univ. de Alicante, 1988, 268 pp.

LA ROCA, N. "Deslizamiento rotacional -colado de jango en los Valles de Alcoy (Mas de Jordá-Benillup)", Cuadernos de Geografía, no 26, Dpto. de Geografía, Univ. de Valencia, 1980, pp. 23-40.

LACOSTE, A. - SALANÓN, R., Biogeografia, Oikos, Barcelona 1973, 271 pp.

LÓPEZ GÓMEZ, A., ROSSELLO VERGER, V. y otros, Geografía de la provincia de Alicante, Diputación Provincial, Alicante, 1978, 608 pp.

Mapa Geotécnico y de riesgos geológicos para la ordenación urbana de Alcoy E 1:25.000, I.G.M.E., 225 pp.

MARTÍNEZ, W. y otros, Mapa Geológico de España. E 1:50.000. (846), I.G.M.E., Madrid, 1978.

MARTÍNEZ, W. y BENZAQUEN, M., Mapa Geológico de España E 1:50.000. Onteniente (820), Madrid, 1975 , $49 \mathrm{pp}$.

MATARREDONA, E., "Los depósitos de ladera de la Serra de Serrella (Alicante)”, Investigaciones Geográficas, $\mathrm{n}^{\circ}$ 6, Instituto Universitario de Geografía , Alicante, 1988, pp. 69-93.

NEBOIT, R., L'homme et l'erosión, Ass. des Publ. Fac. des Leares et Sciences Humaines de Clermont Ferrand, 1983.

RODRÍGUEZ ESTRELLA, T., "Síntesis geológica del Prebético en la provincia de Alicante" B.I.G.M.E., Madrid, 1977, pp. 183-214.

ROSSELLO VERGER, V., "Los canchales de montaña calcárea y los factores termoclásticos" Actas de la II Reunión Nacional del Grupo Español de Trabajo del Cuaternario, Madrid, 1977, pp. 223-233.

TRICART, J. et KILIAN, J., L'eco-geographie et l'amenagement du milieu naturelle, Lib. François-Maspero, Paris, 1979.

TRICART, J., La Tierra, planeta viviente, Akal, Madrid, 1972, 171 pp.

VARIOS, La Font Roja, Ayuntamiento de Alcoy, 1982. 